\title{
SECCIÓN ABIERTA
}



REVISTA DE DERECHO UNED, NÚM. 12, 2013

\title{
LA TEOLOGÍA POLÍTICA DE CARL SCHMITT Y LA TEOLOGÍA POLÍTICA DE ÁLVARO D’ORS: UNA DIFERENCIA DE PRINCIPIOS
}

\author{
CARL SCHMITT'S POLITICAL THEOLOGY AND THE ÁLVARO \\ D'ORS'S POLITICAL THEOLOGY: A PRINCIPLES DIFFERENCE
}

\author{
GaBRiEl GuillÉN KALlE \\ Doctor en Derecho por la U.C.M. \\ Prof. Dr. Ayudante ANECA
}

Resumen: Schmitt introdujo el término Teología Política en 1922. Álvaro d'Ors acusa al de Plettenberg de realizar una teoría parcial al ligarla al concepto de soberanía, a la excepcionalidad y a su concepto de lo político y a su antiuniversalismo. D'Ors por el contrario es universalista, basado en la Iglesia y en el Reino de Cristo; su Teología política no pretende la Soberanía, pues sería siempre usurpada, ya que el único Soberano total y universal es Cristo. Fiel reflejo de esto es la no autonomía de lo político principio opuesto al que mantuvo el maestro renano.

Abstract: Schmitt introduced the concept of Political Theology in the Political Theory in 1922. Álvaro 'Ors refuted to the Plettenberg master to make a partial description when connected there with his sovereign concept, in an exceptional term, an with his political concept, all this link to antiuniversalism. Contrary d'Ors stay as an universalist, with reason in the Church and in the Christ Kingdom; his political theology don't want a sovereign, perhaps should he ever usurped, there the only full and universal sovereign is Christ. Faithful view of these is his negative to the authonomy of the political contrary principle as who sustented Schmitt. 
Palabras clave: Teología política, Carl Schmitt, Álvaro d’Ors.

Key words: Political Theology, Carl Schmitt, Álvaro d’Ors.

Recepción original: 08/05/2013

Aceptación original: 09/05/2013

Sumario: 1. Aclaraciones previas. 2 Diferencias de la Teología política en Schmitt y d’Ors. 3. La Teología política en Schmitt. 4. Alcance del nuevo concepto. 5. Reflexiones sobre la Teología política y su aplicación. 6. Diferencias entre la teología política schmittiana y dorsiana. 7. La Teología política según d’Ors.

\section{ACLARACIONES PREVIAS}

En un artículo de $1976^{1}$, Álvaro d'Ors reconocería que Schmitt era el primer introductor del término Teología política, el lo recepcionó, mas se mostraba crítico y distante frente a sus posiciones. La diferencia está en la concepción que ambos sustentan sobre la problemática de la legalidad y la legitimidad, sobre el tema de orden y derecho. Ya lo explicó el profesor d'Ors, con mano maestra, cuando dibujo el problema y la diferencia que existía entre ambos. Schmitt indicaba que él cambiaba espacio por tiempo; y este juicio era algo más que una declaración de principios. Para Álvaro d'Ors era «algo que excede de la congruencia de una sensibilidad diacrónica tan admirable como la de Carl Schmitt y no acabada de entenderse bien $»^{2}$. Para d'Ors el jurista, y el lo era, debía entender el derecho como algo histórico, algo que no es comprensible sino en un momento temporal; dentro de la dimensión cronológica. Para d'Ors, con razón, Schmitt se estaba mostrando más como político que como jurista, pero, dirá a renglón seguido, que esto es algo normal, o, por lo menos no extraño entre los yuspublicistas ${ }^{3}$. Podemos decir, sin ambages, que la Teología Política de Carl Schmitt es más política que Teología, y que la Teología Política de Álvaro d’Ors es más Teología que política.

Schmitt para dar un carácter pragmático a sus teorías debe «politizarlas», según su archiconocido concepto de lo político, que afecta como se pueda analizar hasta su teoría de los «órdenes concretos». Para Schmitt el orden es esencial, en palabras de Gonzalo Fernán-

1 Álvaro d'Ors, «Teología política: una revisión del problema» Revista de Estudios Políticos, enero-febrero, 1976, pp. 41-77.

2 Álvaro d'Ors, «El «Glossarium» de Carl Schmitt», en Estudios sobre Carl Schmitt, coordinados por Dalmacio Negro Pavón, Madrid, Veintiuno, 1996, p. 23.

3 Ibid., p. 23. 
dez de la Mora, «es el orden el fin que da sentido a todas las formas políticas», y como señala Dalmacio Negro Pavón: «La superioridad de la civilización occidental podría explicarse tal vez por la viva conciencia del Derecho como elemento fundamental del orden vital humano» ${ }^{4}$.

Ya dijo, con cierta ironía y carácter mesiánico, Schmitt en su obra autobiográfica, "Ex capitivitate Salus», que si antes, en el siglo XVI, Alberico Gentile mandó callar a los teólogos, hoy habría que hacer lo mismo con los juristas. Para él debían de hablar los políticos que deciden, pues como preguntaba en su obra Glossarium, 1950, a Helmut Schelsky ¿qué es y dónde está la ciencia europea del Derecho? ${ }^{5}$.

Este agudo sociólogo se mostraba crítico respecto al concepto del amigo-enemigo de Carl Schmitt y si se había modificado con los cambios técnicos y de la prensa, que han abierto modificaciones no sólo cuantitativas sino cualitativas en la comprensión de lo político.

\section{DIFERENCIAS DE LA TEOLOGÍA POLÍTICA EN SCHMITT Y D'ORS}

Schmitt es el introductor del concepto Teología Política, pero ¿en qué sentido debe entenderse esta nueva concepción política? Es cierto, dirá d'Ors, que el tema tal y como suele presentarse fue introducido por Carl Schmitt en 1922 y dirá «la expresión iba a tener fortuna y en varios sentidos, pues servía para abarcar muy distintos aspectos de posibles relaciones entre teología política» ${ }^{6}$.

D'Ors se quejaba de la estrechez que supone un subtítulo que indicaba sin dudas que planteaba la relación entre teología política a propósito del tema de la soberanía. Así dirá d'Ors: «Francamente, la conexión interesaba a Schmitt como fundamento de su concepto de la soberanía: el milagro, como excepción al orden natural, venía a justificar el poder de excepción en el orden político, y el descrédito del mismo venía a desacreditar el constitucionalismo liberal del «Rey que reina pero no gobierna». Se centraba así en el problema de

4 Dalmacio Negro Pavón, «Orden y Derecho en Carl Schmitt», en Estudios sobre Carl Schmitt, p. 344.

5 Ibíd., p. 345. Una de las más agudas visiones de la teoría amigo-enemigo puede encontrarse en Helmuth Schelsky, Politik und Publizitat, Stuttgart- Degerloch, Seewald Verlag, 1983.

6 Álvaro d’Ors, «Teología política...» op. cit., p. 42. 
la teología política en el plano de una realidad histórica moderna ya muy secularizada, es decir, desteologizada ${ }^{7}$.

Álvaro d'Ors analizará con pormenores el planteamiento schmittiano de la Teología política: su conclusión es que es una visión bastante limitada, pues se reduce el problema de la soberanía del Estado a la Edad Moderna; eso sí valora la importancia doctrinal de este problema y su claridad, expuesta en dicotomías y conceptos políticos. Esa visión, reconocerá d'Ors, la siguió en otros escritos, así en Römischer Katholizismus und politische Form $(1923)^{8}$. Como indica d'Ors Schmitt sostiene que «la Iglesia, además de su forma sobrenatural, constituida por su carácter y misión espirituales, postuló la forma política que representan el orden natural histórico aquella otra idea sobrenatural que la constituye: una forma de cívitas humana extraña a todo condicionamiento económico. En virtud de ella está presente la Iglesia en el mundo como una forma de poder histórico universal (Weltgeschichtliche Machtform). Esto es un dato de capital importancia para todo planteamiento de la teología política, pues, independientemente de las posibles interferencias de la acción de la Iglesia jerárquica o de los fieles en pro o en contra de determinadas formas de existencia política, no debe olvidarse que la Iglesia misma se presenta con una forma política propia, cuya posible influencia en consideración a las otras formas políticas de carácter económico supone ya un problema» ${ }^{9}$.

\section{LA TEOLOGÍA POLÍTICA EN SCHMITT}

El libro de Schmitt de 1922 sobre la Teología Política es crucial en el conocimiento de Carl Schmitt, ¿hay que situarlo dentro de la renovación católica, como se ha indicado? En opinión de Paul Noack no se trata de un producto del catolicismo. Schmitt es cierto fue siempre católico, aún cuando realizó unos curiosos matrimonios por el rito ortodoxo, ahora bien, él lo que pretende es edificar su filosofía política con ese escrito, y ello no era posible sin situar la piedra angular que es el concepto de soberanía ${ }^{10}$. La primera definición es sumamente elocuente: "Soberano es el que decide sobre el estado

\footnotetext{
$7 \quad$ Ibid., p. 42.

8 Traducido al castellano por Carlos Ruiz Miguel (Catolicismo y forma política), $\mathrm{y}$ un «Estudio preliminar» del mismo autor, Madrid, Tecnos, 2000.

9 Álvaro d'Ors, op. cit., p. 44. Ese planteamiento seguirá en la obra de Carl Schmitt.

10 Paul Noack, Carl Schmitt. Eine Biographie, Berlín, Propylän Verlag, 1991, p. 70.
} 
de excepción»; la segunda definición también lo sitúa ante la gran problemática que luego desarrollarían posteriores escritos: «Todos los conceptos jurídicos son conceptos teológicos secularizados ${ }^{11}$. En este punto cobra importancia el tema de la decisión (Entscheidung), que iba a desembocar en una bifurcación de dos vertientes, como ha tenido ocasión de exponer Giacomo Marramao: de un lado, a situar la política en una esfera extra normativa; de otro, en el estado de excepción que suspende la norma, determinar con plena autonomía un nuevo reagrupamiento amigo-enemigo ${ }^{12}$. En este punto es el que se relaciona a Schmitt y a Benjamín, pues ambos elaboran una filosofía de la historia, el primero en términos católicos y el segundo en términos de la religión judía. Schmitt al elaborar el concepto de Teología Política opta por dejarlo abierto.

\section{ALCANCE DEL NUEVO CONCEPTO}

¿Cuál es el concepto de Teología Política de Carl Schmitt? y ¿cómo desarrolla tal concepto? y, por último ¿qué efectos han tenido en el pensamiento universal? Vamos a desarrollar dicho concepto en cuatro fases: A) Teología política como historia del concepto de soberanía. Para Schmitt todo concepto político es un concepto teológico secularizado. El Estado, los símbolos que lo sostienen y fundamentan tienen una carga religiosa, que en el mundo occidental son mayoritariamente católicos, aunque también se mezclan con elementos protestantes. Así la omnipotencia de Dios se lo otorga a los monarcas que son representantes divinos en la tierra, luego se otorga al pueblo o, incluso, al legislador. Schmitt trata de otorgar al concepto de soberanía una realidad política y como pensador de la acción política se sitúa a la altura de pensadores como Maquiavelo, Hobbes, Vico, Nietzsche y Sorel. Resulta gráfico cuando Schmitt habla de la edición de Leviatán de Hobbes de 1651 y recuerda, como es lógico que produzca «una impresión excepcional: un hombre gigantesco, compuesto por innumerables hombres pequeños, tiene en el brazo derecho una espada y en la izquierda un báculo episcopal que protege una ciudad pacífica» ${ }^{13}$. Debajo se mostraban los símbo-

11 Carl Schmitt, Politische Theologie (1922), utilizo la 6. ${ }^{\text {a }}$ edición de 1993, Berlín, Duncker 8 Humblot.

12 Giacomo Marramao, Poder y Secularización, Barcelona, Península, 1989, p. 238. La neutralización y el control de las tensiones conflictivas no se producen en la forma dialéctica de la superación (Aufhebung), sino en términos de un desplazamiento lateral de un centro a otro.

13 Carl Schmitt, El Leviatán en la teoría del Estado de Thomas Hobbes, Madrid; Haz, 1941 (trad. De F. Javier Conde), p. 25. 
los, una espada, una corona, el cañón, los fusiles, lanzas, banderas y, por último, una batalla. La creatio ex nihilo, creaciones de la nada, es otro rasgo del catolicismo. El catolicismo mediante el milagro rompe la normalidad. El milagro es la excepcionalidad. Legitima nuevas situaciones y desentumece la realidad. Para Schmitt, la soberanía es una "situación de hecho", una aplicación del Derecho, mientras que para Kelsen, la soberanía sería una abstracción de los juristas, una formulación ideológica ${ }^{14}$. B) Una teoría de la soberanía universal. Esa es la intención de Schmitt, que trata de otorgarle una brizna de razonabilidad, aunque se estrella en la voluntad de cada uno, pues como indica el propio Schmitt, siguiendo a Goethe, «aún hoy ser hombre sigue siendo una decisión». Lo importante para Schmitt es anclar al estado soberano como modelo de interpretación política central. Schmitt proyecta sobre Hobbes su propia idea de soberanía. Esta idea la desarrolla en la Teología Política de 1922. El Estado moderno solamente se afirma como poder soberano reprimiendo la resistencia revolucionaria. Como recuerda Habermas, rememorando a Schmitt: «El Estado es la perpetua guerra civil impedida. Su dinámica es la opresión de la revuelta, la perpetua sujeción de un caos que tiene su fuente en la naturaleza más mala de los individuos» ${ }^{15}$.

Como se tenido ocasión de expresar, la nota peculiar del Estado es la capacidad de decidir respecto a los casos excepcionales o, expresándolo con una mayor precisión, la de producir la excepción o sea, suprimir la ley vigente. Así expone Fischbach, que Kantorowicz trató de solucionar dentro del ámbito de la escuela libre del Derecho este problema. Kantorowicz define al Estado como «sujeto de derechos de dominio jurídicamente inalienables, sobre un territorio y sus habitantes ${ }^{16}$. Kantorowicz argumentaba de una manera práctica al aducir que según el artículo 18 de la constitución del Weimar, el Reich era un Estado unitario, a pesar de otorgar a los Länder una autonomía, sin poner en peligro la unidad. De esta manera sostenía un concepto de Estado liberado del concepto de soberanía. C) La teología política y el concepto de lo político. En Schmitt resultan inseparables, pues une la Teología política con el concepto de lo político, o sea, con la distinción amigo-enemigo. Schmitt, como es sabido, distingue al hostis del innimicus, al cual la Biblia nos conmina a respetar; pero nos hallamos en un mundo secularizado en el que lo

14 Vittorio Frosini, «Kelsen y las interpretaciones de la soberanía», en Revista Española de Derecho Constitucional, 1991, pp. 61-74. En especial, p. 66.

15 Jürgen Habermas, Identidades nacionales e internacionales, Madrid, Tecnos, 1989 , p. 70 .

16 Oskar G. Fischbach, Teoría General del Estado, Barcelona, Buenos Aires, Labor, 1926. (3. ${ }^{\mathrm{a}}$ edición 1934) pp. 138-139. 
político se decide por él «fenómeno de la lucha en el deslinde de la propia identidad contra la actividad de un enemigo que amenaza la propia existencia, por la situación de guerra que implica a todo un pueblo y por la situación de guerra civil» ${ }^{17}$.

En Schmitt nada es accidental, así hay que considerar a su Teología política (1922) como la continuación de un libro suyo anterior, La Dictadura (1921), donde trato de renovar el concepto de poder soberano en sus capas semántica revolucionarias, como diría con acierto Habermas ${ }^{18}$.

En su obra de 1970, Politische Theologie II, dirá Schmitt, que «todo el mundo está necesitado de cambio y renovación, se produce el dualismo agnóstico del Creador y del Redentor, que logra hacer enemigos a los representantes de mantener el orden y torna en inevitables a los revolucionarios ${ }^{19}$.

Ya vimos que Álvaro d'Ors cree que Schmitt reduce el problema de la Teología política al de la soberanía del Estado y la circunscribe a la Edad Moderna, todo ello se debe a: D) La Teología política y la antropología schmittiana. Schmitt es pesimista y d'Ors un optimista, la fe le impide en los momentos de giro más catastrófico sentirse pesimista; su idea religiosa, su cristianismo, le permiten observar la vida con serenidad, para el nada es catastrófico. La serenidad la garantiza su fe. El cristiano puede ante cualquier adversidad enderezar su última voluntad libre, pues para el cristiano, aun con cualquier situación imprevista, embarazosa, encuentra en su actitud cristiana una respuesta clara y segura, sobre todo, cuando nos reclaman desde arriba.

Schmitt es un pesimista recalcitrante; el se burla del decisionismo del mismísimo Bodin de quien dice, no le parece un auténtico decisionista. Para Schmitt, Bodin, practicó un tipo impuro de decisionismo, puesto que la decisión jurídica para Bodin supone un previo orden o sistema de principios con validez originaria, de donde la decisión, extrae su contenido y su validez ${ }^{20}$.

Pero es más, también en este aspecto se separa Schmitt de otro ilustre pensador tradicional-católico: Donoso Cortés, quien dibujase

17 Jürgen Habermas, op. cit., p. 68.

18 Ibid., p. 68.

19 Carl Schmitt, Politische Theologie II, Berlín, Duncker 8 Humblot, 1970, manejo la 3. ${ }^{a}$ edición de 1990 , pp. 120 y ss.

20 Eustaquio Galán y Gutierrez, «Los tres tipos fundamentales del pensamiento jurídico a la luz de la «Perennis Philosophia» en Revista General de Legislación y Jurisprudencia, abril 1955, p. 400. 
la lucha del Bien y del Mal en la historia, con el probable triunfo del mal. Se trataba de una idea con tintes maniqueos y apocalípticos de los cuales Schmitt trato de huir ${ }^{21}$. Schmitt apreciaría en Donoso ese carácter decisorio que sólo se puede hallar en pensadores que tocan la realidad política, usando una expresión muy de su gusto, que eran «intelectuales aventureros». Como expone Schmitt, «Donoso Cortés aun careciendo del pensamiento psicológico dialéctico del nórdico (Sören Kierkegaard) y de sentido hegeliano de la historia, se percató de un modo exacto, que en la pseudo religión de la humanidad absoluta es el principio de un camino que conduce a un terror inhumano» ${ }^{22}$. Para Schmitt, comprender a Donoso «es como comprender a Nietzsche, como fosforescencia de sus impresiones, no como sistema, sino como vida e ingente destino» ${ }^{23}$.

Schmitt a pesar de mantener un criterio ambivalente respecto a Hobbes, reconoce que fue el pensador que halló la fórmula definitiva del decisionismo: auctoritas veritas, non facit legem. La decisión soberana -dice Schmitt- es la que funda tanto la norma como el orden. El soberano decisorio no es competente para decidir en virtud de la legitimación que otorga un orden ya existente de antemano. Sólo es la decisión que le hace soberano y lo que hace posible toda posterior ley y orden ${ }^{24}$. Así las cosas, es difícil admitir a los discrepantes. El Estado tiene siempre que asirse a medidas dictatoriales, cuando el soberano que tiene monopolio de las diferencias amigo-enemigo, puede ponerse en peligro.

Quizá, aunque se haya utilizado como tal, (en España desde Adolfo Posada), el concepto de lo político no es belicista, es excepcional o innormal; también queda claro que Schmitt no se ocupó en ningún caso de las condiciones de paz. Schmitt adopta un concepto de «peligro» similar al que manejó Ernst Jünger en Tormentas de acero, al referirse a la Primera Guerra Mundial «el pueblo fundido en la lucha a vida o muerte afirma su propia peculiaridad tanto contra los enemigos externos, como contra los Traidores en las propias filas ${ }^{25}$.

Schmitt cree, siguiendo las apreciaciones de Nietzsche, que la intensidad distante procede de la libertad, de la espontaneidad absoluta de la nada. Tales instantes, como era de esperar, son estados de ex-

21 Francisco J. Conde, «La idea actual española de nación» (1939), incluido en Escritos y Fragmentos politicos, Madrid, I.E.P., 1974, p. 347.

22 Carl Schmitt, Interpretación europea de Donoso Cortés, Madrid, Rialp, 1952, p. 62 .

\footnotetext{
23 Ibid., p. 63.

24 Eustaquio Galán y Gutierrez, op. cit., marzo 1955, p. 261.

25 Véase Jürgen Habermas, op. cit., p. 68.
} 
cepción, pues, a juicio de él, sólo a partir de esta excepción se pone de manifiesto lo que normalmente en la vida regular permanece oculto. Así el pensador alemán, Rüdiger Safranski, señalaría las frases de Schmitt que demuestran la predilección que éste tenía hacia lo excepcional. Así dirá: «Lo normal no prueba nada, la excepción lo demuestra todo. En la excepción la fuerza de la vida real rompe la certeza de una mecánica petrificada en la repetición ${ }^{26}$. Se tratan de conocidos párrafos extraídos de la Teología Política (1922) de Schmitt, donde insiste que existen decisiones que «vistas normativamente han nacido de la nada». En opinión de Safranski, «la fuerza de la decisión no tiene otro fundamento que la voluntad del poder; en lugar de la legitimación se introduce la intensidad de un instante originario ${ }^{27}$.

En la concepción schmittiana, el Estado vive en un perpetuo estado de excepción, soberano es el que decide sobre el estado de excepción. Además, como dice Safranski, Carl Schmitt confiesa el contenido teológico de su concepto de soberanía. «El Estado de excepción tiene para la jurisprudencia una significación análoga a la del milagro para la teología. En el milagro se revela la soberanía de Dios, y en el estado de excepción se revela la del Estado» ${ }^{28}$.

\section{REFLEXIONES SOBRE AL TEOLOGÍA POLÍTICA Y SU APLICACIÓN}

He tratado de analizar la Teología Política de Schmitt, en este momento hay que acudir a la concepción que mantuvo Álvaro d'Ors. Para d'Ors la postura de Schmitt, como la de cualquiera que se han intrincado en el tema, era una postura parcial y, a su decir, ha faltado, quizá, una visión totalizadora. Schmitt introduce el término, pero proyecta la teología política en la interpretación del proceso de secularización política, o lo que es lo mismo, en un proceso de desteologización del pensamiento europeo ${ }^{29}$. Para d'Ors la soberanía arranca de Jesucristo, quien tiene poder originario. De esta forma no cabe contestación, se cree o no se cree. Todos los soberanos no son más que delegados que deben mandar en nombre de Jesucristo; según Álvaro d'Ors poder «constituido» es poder socialmente reconocido, es decir, potestad. Lo que importa -según d'Ors- es calcular las condiciones que debe reunir una persona para que pueda ostentar

26 Rüdiger Safranski, Un maestro en Alemania. Martin Heidegger y su tiempo, Barcelona, Tusquets, 1997, (1. a ed., septiembre), p. 213.

27 Ibíd., p. 213.

28 Ibid., p. 213.

29 Vid. Álvaro d’Ors, «Teología política...» op. cit., p. 64. 
esa potestad y, por ello, existe un deber moral de obedecerle ${ }^{30}$. Distingue entre legitimidad de origen y ejercicio que se da en el poder político, y para la pertenencia a la Iglesia como «hijos de Dios». Para d'Ors tan sólo el poder legítimo será el que resulte conforme al derecho divino y a una tradición concreta de la comunidad que se trata, según su identidad histórica; aunque ése magma tradicional no pueda pretender nunca la misma equidad y universalidad del derecho divino $^{31}$. El esquema que utilizó Álvaro d'Ors entronca con nuestro siglo de oro, la neoescolástica, a la que Schmitt dijo refiriéndose al Molina S.I. de Fraga, que no enseñaba a decidir. Para d'Ors el concepto de la legitimidad lleva a la necesidad de un Teólogo político, pues es legítimo el poder mandado por Dios ${ }^{32}$. Álvaro d'Ors soluciona el problema del abuso del poder o del tiranicidio según la fórmula clásica en el siglo de oro, tal y como lo hacían el padre Mariana o Francisco Suárez, aún con una interpretación «sui generis» ${ }^{33}$.

Esto le llevara a d'Ors a considerar a la ciencia política, como una ciencia ajena a la ciencia social, con las negativas consecuencias que esto lleva, pues no estudia hechos, sino doctrinas, es decir, libros acerca de la Prudencia política (también manejaría ese criterio, y quizá de éste proviene, Rafael Gubert, que concibe la historia del Derecho como la historia de los libros ${ }^{34}$. Para Álvaro d'Ors, el concepto religioso que él mantenía, iba unido a la violencia que impone el orden; su juicio, en la familia reina el Amor, y la hostilidad esencial trasciende toda la vida política del Estado; también otro gran jurista Luis Legaz Lacambra opondría Derecho y amor, lo que sucede es que Legaz ataca la posición de Schmitt y de su concepto de lo político y la opone un seráfico concepto de amor ${ }^{35}$.

Está claro que para d'Ors, «la democracia obedece a un ideal de igualdad de los ciudadanos y acceso legal al poder, sin consideración de la legitimidad ${ }^{36}$. Para d'Ors la legitimidad es la divina y no reconoce los tres tipos ideales que diseña Max Weber, o los dos que mantenía su amigo Carl Schmitt.

La voluntad democrática puede expresarse mediante el acto de «plebiscito» o de «referéndum»; Álvaro d'Ors siente siempre cierta

\footnotetext{
30 Álvaro d'Ors, La violencia y el orden, Madrid, Ediciones Dyrsa, 1987, p. 59.

31 Ibid., pp. 9-10.

32 Ibíd., p. 50.

33 Ibid., pp. 62-63.

34 Álvaro d'Ors, Una introducción al estudio del derecho, Madrid, Rialp, 1963, p. 107.

35 Cfr. Luis Legaz Lacambra, El Derecho y el amor, Barcelona, Bosch, 1960.

36 Álvaro d'Ors, Una introducción..., p. 128.
} 
prevención hacia la partitocracia. Plantea problemas tales como la financiación y otros, para él, los partidos políticos no son representantes de opinión pública. El derecho es producto de la autoridad, y no interviene fuerza, pues carece de violencia; pero la violencia se extiende como fuerza contra el orden, pero también el orden puede ser resultado de una violencia. La violencia -a su entender- tiene dos sentidos: fuerza que impone un orden, y fuerza que descompone el orden $^{37}$. Con un quiebro a la teoría de San Francisco de Sales dirá que: «Sin una posible violencia que imponga, no puede haber un orden propiamente dicho. Todo orden presupone una violencia constituyente y ejecutiva, aunque también puede ser este orden subvertido por una violencia contraria ${ }^{38}$.

\section{DIFERENCIAS ENTRE LA TEOLOGÍA POLÍTICA SCHMITTIANA Y DORSIANA.}

Para Álvaro d'Ors la política, como hacer humano, es un hacer práctico y no puramente técnico. En su concepción los principios morales de la Moral privada no dejan de ser aplicables a la conducta privada, eso sí según modalidades, y según diferencias personales. Su ejemplo es que no mentir, no matar, no hurtar son aplicables a la acción política. Su concepto de política es tan ético que tan sólo podía ser desarrollado por hombres santos, plenos de autorictas; además esos principios a que alude son la salsa de la misma en la práctica, si un político dijese siempre lo que opina, la verdad no sería político; para ello me remito a la teoría de Ortega en el Mirabeau y el político, muy discutida ella, entre ellos por Francisco Ayala, pero que no deja de tener un fondo de realismo: el político que engatusa a la opinión pública y el científico que busca la verdad; también las conferencias que dio Max Weber: la política como vocación y el científico como vocación.

Álvaro d'Ors se opone radicalmente a Schmitt quien en un realismo político clásico (Maquiavelo, Hobbes, Gramsci, etcétera), mantiene la autonomía de lo político, lo político que distingue entre amigos y enemigos. Para d'Ors «la no-autonomía de la política no quiere decir que la doctrina cristiana tenga criterios concretos para cualquier tipo de actividad política, sino que hay límites morales para tal actividad. Así se explica la compatibilidad de esa no-autonomía con la libertad política, que significa la moralidad de cualquier

37 Álvaro d'Ors, La violencia y el orden, op. cit., p. 74.

38 Ibíd., p. 75. 
opción política que no sea inmoral; al ser indiferente, ya sea moral, como es moral, en el ámbito personal, cualquier conducta que sea realmente indiferente y no vaya contra la ley de Dios ${ }^{39}$. Para d'Ors, aun cumpliendo con la ley de Dios y no siendo indiferente a lo religioso resulta incorrecto hablar de una "política cristiana», pero es deseable -a su juicio- que un orden político del mundo se contuviese en los límites del Cristianismo ${ }^{40}$. Aquí se vuelve a mostrar d'Ors universalista y Schmitt como antiuniversalista que no cree en un concepto de Humanidad; sin embargo Álvaro d'Ors dirá que «cualquier ensayo político que sea anticristiano necesariamente está impedido de constituir un orden deseable, un bien para la Humanidad» ${ }^{41}$.

\section{LA TEOLOGÍA POLÍTICA SEGÚN D’ORS}

Como repite muchas veces, el cristianismo tiene libertad general según sus opciones políticas con dos límites: la moral ratione peccati y la responsabilidad personal. No se exige en los cristianos, a los fieles de una determinada comunidad política, la unidad de acción política, con excepción de que la prudencia aconseje la unidad para que la división no favorezca una agresión de los enemigos de la Igle$\mathrm{sia}^{42}$. Para d'Ors se trata de evitar las agresiones de los enemigos, de esta forma, cada cristiano podría pensar libremente, y ello, se lograría mediante un reconocimiento oficial en la comunidad política en aquello que la Iglesia considera esencial. Todo ataque a la Iglesia relativo a estos principios esenciales debe ser considerado como un ataque a la comunidad política misma ${ }^{43}$. Estaríamos dentro de la teoría de los órdenes concretos de Schmitt, simplemente que el teutón hablaba de la esencialidad de un pueblo, y no a la universalidad de la Iglesia y, con ello, estaríamos cerca de los yuspublicistas cristianos Hauriou o Renard con su institucionismo.

¿Cuál es la Teología política de Álvaro d’Ors? Del Dogma de la Realeza de Cristo no se deriva en razón, dirá él, la necesidad de un régimen monárquico, como de la omnipotencia divina que Cristo tiene como Dios. Dirá d'Ors que: «Derivaciones de este tipo no cons-

39 Álvaro d'Ors, La violencia y el orden, op. cit., p. 114.

40 Ibid., p. 114.

41 Ibid., p. 115. Su universalismo se opone al antiuniversalismo de Schmitt.

42 Álvaro d'Ors, «Teología política...», p. 65.

43 Ibíd., p. 66. "Como hemos dicho, puede hacerlo así precisamente para poder salvar su libertad política y evitar la necesidad del partido cristiano único». 
tituyen una verdadera teología política, precisamente por su carácter metafórico ${ }^{44}$.

Álvaro d'Ors nos dirá que: «En este sentido, creo que el único dogma del que se pueden obtener consecuencias políticas es el que Cristo es Rey, a la vez que Legislador y Juez. Debemos tratar, pues, de este dogma cristiano y luego de sus racionales consecuencias políticas ${ }^{45}$. A su juicio una teología política no puede ser teología moral o espiritual. Dirá que «aunque Cristo declaró expresamente que su realeza no era comparable a la de los reinos carnales, y por ello no quiso ejercer su potestad judicial, sin embargo, El mismo reconoció su soberanía total universal, adquirida a título de herencia y a causa de la Redención ${ }^{46}$.

Álvaro d'Ors trata de salvar el impedimento de identificar al Reino de Cristo con la Iglesia actual, de esta forma la soberanía de Cristo no sería actualmente universal; «por otro lado, siendo la Iglesia el Cuerpo Místico de Jesucristo, resultaría que un Reinado de Cristo sobre la Iglesia quedaría reducido a serlo sobre Sí mismo, sobre su cuerpo Místico ${ }^{47}$. Álvaro d'Ors trata de salvar dicha dificultad, considerando que el Reinado de Cristo está en cada uno de los fieles, coincide con la Iglesia -fuera de la que no hay salvación-, pero existe fuera de ese ámbito. Para d'Ors en un primer sentido se puede hablar de un Reinado de Cristo moral, pero en el segundo de una realidad teológico-política ${ }^{48}$. Álvaro d'Ors fundamenta la doctrina de su Teología política en las Encíclicas papales y «la consecuencia política del Reinado de Cristo Rey es descubrir toda pretensión de poder político absoluto, sea autocrático sea democrático, pues la forma de concretarse la voluntad no interesa a este respecto; es decir, la exclusión de toda otra "soberanía» ${ }^{49}$.

Para él, la negación de la estructura estatal, y esto le vuelve a diferenciar de Schmitt, tal y como se entiende esta desde Bodin, debe considerarse como exigencia de una recta teología política cristiana.

\footnotetext{
44 Ibid., p. 72.

45 Ibid., p. 72.

46 Ibíd., pp. 72-73. «Pertenece también al carácter monárquico de esta realeza de Cristo el que se asocia a ella su Madre, que es considerada también ella Regina. En efecto, corresponde a la más íntima esencia de la Monarquía legítima el que la realeza no pertenezca estrictamente al que efectivamente gobierna, sino a toda su familia».

47 Ibid., p. 74.

48 Ibid., p. 74

49 Ibíd., p. 76.
} 
Un principio capital es que la iglesia (cosas de Dios) no está subordinada al poder civil. Dirá Álvaro d'Ors: «Esto equivale a decir que la «libertad» que la Iglesia reclama siempre frente a los poderes civiles es una consecuencia estricta de la teología política fundada en el Reino de Cristo ${ }^{50}$.

El resumen de la teoría de su Teología política viene indicada en este jugoso párrafo, que aunque en exceso largo, debe, por su claridad y plasticidad, ser reproducido: «Así, pues, si, desde el punto de vista de la teología moral, el gobernante puede verse vinculado en determinados preceptos de prudencia política, desde el punto de vista de la teología dogmática, el propio, como hemos dicho, de la teología política, el precepto es el exclusivamente negativo de no pretender la soberanía, pues sería siempre usurpada, ya que el único Soberano total y universal es Cristo. Y esta misma limitación es la que da consistencia a aquella otra moral política, pues lo que impone este principio de no-soberanía es, ante todo, el sometimiento rendido a la ley de Dios» ${ }^{51}$.

\footnotetext{
$50 \quad$ Ibid., p. 77.

$51 \quad$ Ibid., p. 77.
} 